\title{
Integration of GIS and Remote Sensing for Evaluating Forest Canopy Density Index in Thai Nguyen Province, Vietnam
}

\author{
Duong Thi Loi, Tien-Yin Chou, and Yao-Min Fang
}

\begin{abstract}
Forests are an indispensable part of the natural environment and play a critical role in sustainable development. However, natural forests are being destroyed every year by human activities. Hence, forest management plays a critical role in the sustainable development. Forest canopy density (FCD) is a useful model to evaluate the forest status and changes in a certain period. The advanced vegetation (AVI), bare soil (BI) and canopy shadow (SI) are selected as parameters to study FCD. These parameters are figured out from satellite images. Landsat 8 OLI image - 2015 is first normalized and then manipulated in ENVI and ArcGIS software to calculate the FCD. The overall accuracy of classification result in comparison with the land cover map is $85.3 \%$. The final result shows the distribution of forest canopy density in the study area, consists of dense forest density, moderate forest density, low forest density and non-forest.
\end{abstract}

Index Terms-Forest canopy density, advanced vegetation, bare soil, remote sensing.

\section{INTRODUCTION}

Forest canopy cover, also known as canopy coverage or crown cover, is defined as the proportion of the forest floor covered by the vertical projection of the tree crowns [1]. Mountains and hills, which occupy three-quarters of Vietnam's territory, are the main landscape in Vietnam. Hence, Vietnam has a diverse forest ecosystem. However, the forest has being decreased in both quantity and quality over the years. The forest management becomes an urgent task to maintain and protect the forest ecosystem. Monitoring of forest canopy cover is an essential tool for sustainable management of natural resources [2]. Forest canopy density (FCD) is one of the most useful indices to consider in the planning and implementation of the rehabilitation program [3], [4], and is a major factor in the evaluation of forest status and management interventions [5]. Forest canopy density mapping is one of the most useful parameter to consider in the planning and implementation of afforestation and reforestation programs [6].

Satellite Remote Sensing is used more and more in research. Using the multi-temporal satellite images help to generate the information about land use/land cover. Forest land cover information is often derived from remotely sensed

Manuscript received February 12, 2017; revised May 24, 2017.

Duong Thi Loi is with the GIS Research Centre, Feng Chia University, Taiwan. She is also with Hanoi National University of Education, Vietnam (e-mail: duongloi1710@ gmail.com).

Tien-Yin Chou and Yao-Min Fang are with GIS Research Centre, Feng Chia University, Taiwan (e-mail: jimmy@gis.tw, frankfang@gis.tw). images using classification algorithms [7]. In this study, FCD model is synthesized by the three parameters, including advanced vegetation index (AVI), bare soil index (BSI) and canopy shadow index (SI) [8]. Landsat image is processed in ENVI and ArcGIS software to determine the distribution of FCD in the study area. The aim of this study is to explore the ability of satellite image in assessing the FCD to serve resource management.

\section{STUDY AREA}

Thai Nguyen is a province located in the Northeast region of Vietnam. The geographical coordinate stretches across from $20^{0} 20^{\prime}$ to $22^{0} 25^{\prime}$ North and $105^{\circ} 25^{\prime}$ to $106^{\circ} 16^{\prime}$ East. Thai Nguyen shares its border with six provinces including Bac Can, Vinh Phuc, Tuyen Quang, Lang Son, Bac Giang and Hanoi. Thai Nguyen has many mountain ranges running from the north to the south. The study area is covered in 3541.5 sq.km. Administratively, Thai Nguyen province includes two cities (Thai Nguyen and Song Cong), one town (Pho Yen) and six districts (Dai Tu, Dinh Hoa, Dong Hy, Phu Binh, Phu Luong and Vo Nhai) (Fig. 1). Thai Nguyen is considered as the gateway for socio-economic exchange between the Northeast Area and the Red River Delta.

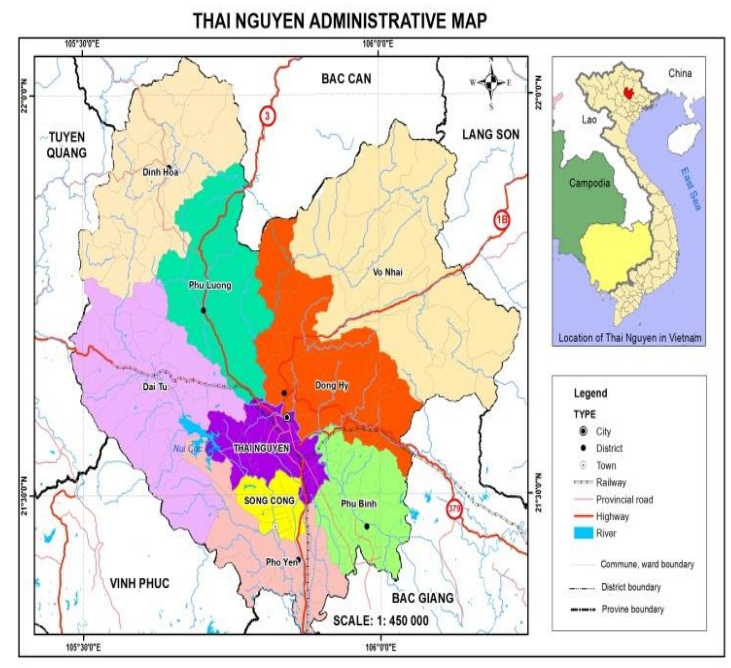

Fig. 1. Thai Nguyen administrative map.

\section{DATA USED}

Satellite Image - Landsat 8 (OLI) taken in October 2016 provided by USGS was used in this study. Its size is 16-bit data and consists of nice spectral bands with a spatial resolution of 30 meters and one panchromatic band with a higher spatial resolution of 15 meters. 


\section{Methodology}

The following steps are used to calculate FCD (Fig. 2)

\section{A. Conversion to TOA Radiance}

Landsat 8 used in this study consists of quantized and calibrated scaled Digital Numbers (DN). It is 16-bit unsigned integer format with range value from 0 to $2^{8}=65536$ [9]. It needs to convert into radiance value to calculate the vegetation indices. This process has been done by using equation (1).

$$
\mathrm{L}_{\lambda}=\mathrm{M}_{\mathrm{L}} \mathrm{Q}_{\text {cal }}+\mathrm{A}_{\mathrm{L}}
$$

where, $\mathrm{L}_{\lambda}=$ TOA spectral radiance (Watts/ $/ \mathrm{m} 2 * \operatorname{srad} *$ $\mu \mathrm{m})$ ).

$\mathrm{M}_{\mathrm{L}}=$ Band-specific multiplicative rescaling factor from the metadata.

$A_{L}=$ Band-specific additive rescaling factor from the metadata.

$\mathrm{Q}_{\text {cal }}=$ Quantized and calibrated standard product pixel values (DN).

\section{B. Calculation of Forest Canopy Density Index}

Three parameters utilized to calculate the Forest Canopy Density Index (FDI) includes Advanced Vegetation Index (AVI), Bare Soil Index (BI) and Shadow Index (SI) or Scaled Shadow Index (SSI). Forest Canopy Density value was calculated in percentage of each pixel by range from 0 to 100 .

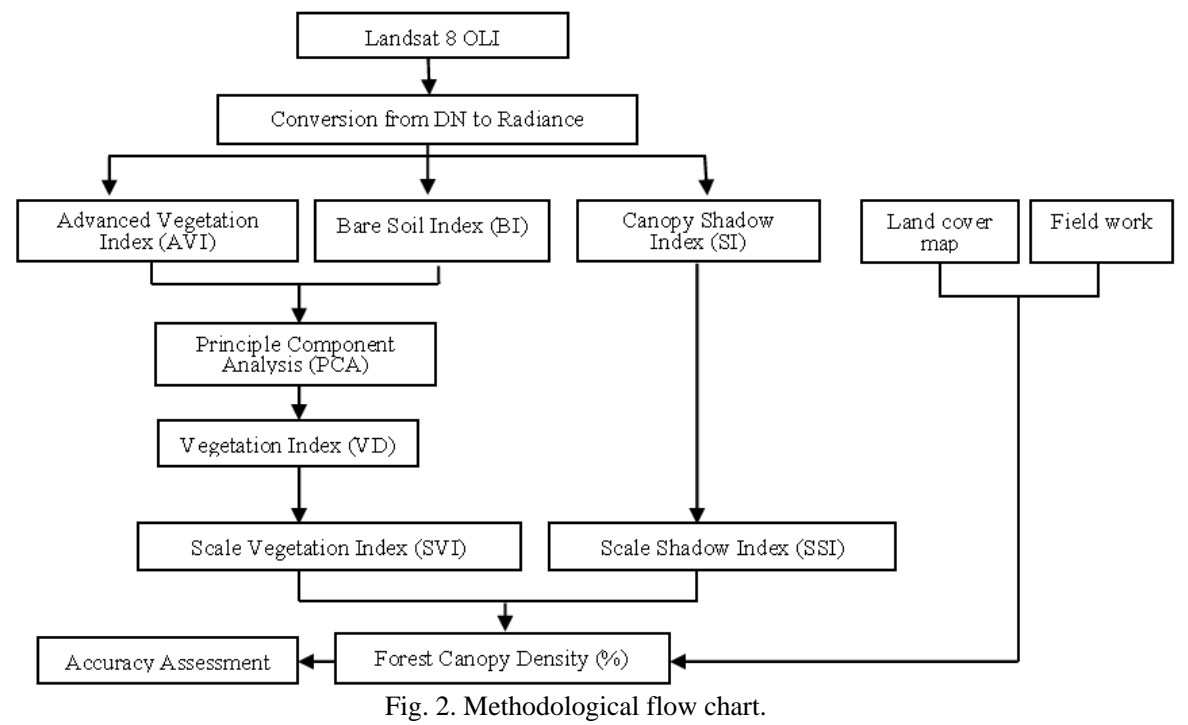

\section{1) Advanced vegetation index (AVI)}

AVI is a one of the essential parameters to determine the healthy vegetation based on the red and near-infrared spectral band. It is similar to NDVI (Normalized Difference Vegetation Index) - the earliest and most widely used vegetation index in remote sensing [10]. However, NDVI is used popularly to classify the high and low vegetation area. It is not reasonable to highlight subtle differences in the canopy density. Therefore, AVI was selected in this study by using power degree of the infrared response. This index is calculated using equation (2). The result is shown in Fig. 3

$$
\mathrm{AVI}=\sqrt[3]{(B 5+1) *(65536-B 4) *(B 5-B 4))}
$$

where, B5 is near infrared band and B4 is red band.

\section{2) Bare soil index (BI)}

BI is combined from blue, red, near infrared and short wave infrared spectral bands to capture soil variations. The short ware infrared and the red band are used to quantify the soil mineral composition, while the blue and the near infrared spectral bands to enhance the presence of vegetation. This index is calculated using equation (3). The result is described in Fig. 4

$$
\mathrm{BI}=\frac{(\mathrm{B} 6+\mathrm{B} 4)-(\mathrm{B} 5+\mathrm{B} 2)}{(\mathrm{B} 6+\mathrm{B} 4)+(\mathrm{B} 5+\mathrm{B} 2)} * 100+100
$$

where, B2 is green band, B4 is red band, B5 is near infrared band and B6 is shortwave infrared band.

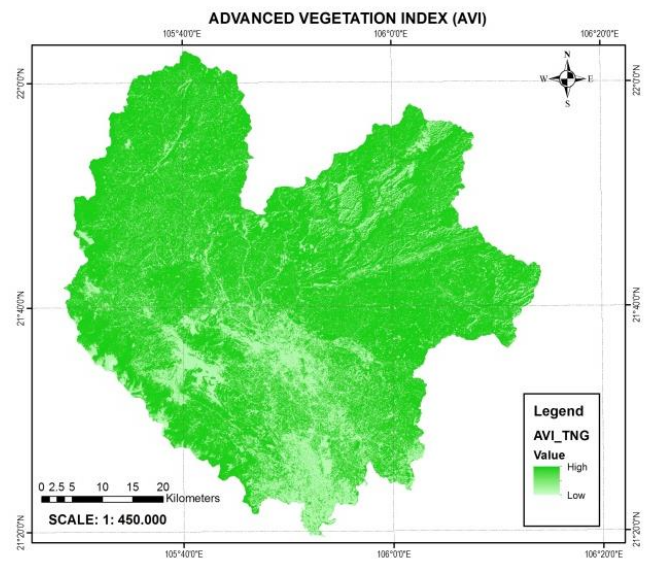

Fig. 3. Advanced vegetation index (AVI).

3) Vegetation density (VD)

VD is carried out by using principal component analysis based on two input parameters AVI and BI. The value of VD is ranged from 0 to 100 percent, and it is expressed in Fig. 5.

4) Scaled shadow index (SSI)

SSI is calculated from Canopy shadow index (SI) by using a linear transformation [11]. The value of SSI is also scaled from 0 to 100 percent. SSI by $100 \%$ responds with the highest possible shadow whereas $0 \%$ responds the opposite [12], [13]. $\mathrm{SI}$ is considered as the main application in forestry and crop 
monitoring because the canopy shadow provides the important information about trees and plants arrangement. This index is often associated with AVI and BSI to understand to reflect the status of vegetation, and it is calculated using the visible bands of the spectrum as the equation (4). The result is shown in Fig. 6.

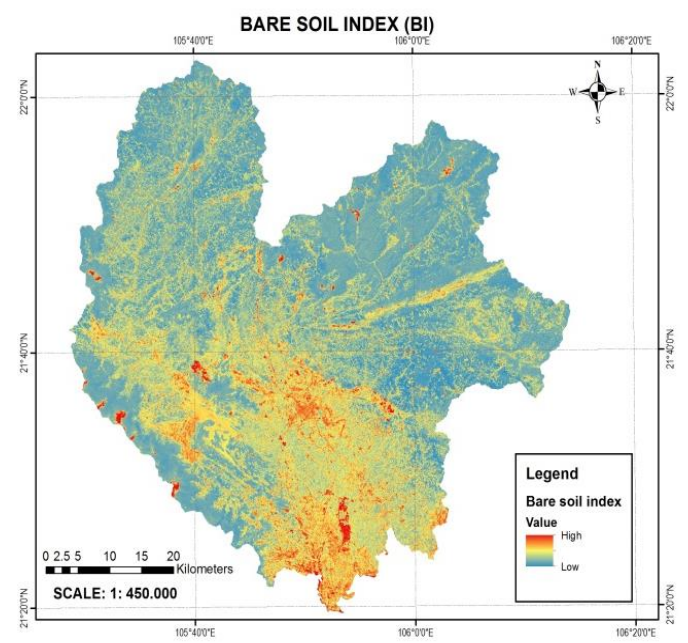

Fig. 4. Bare soil index (BI)

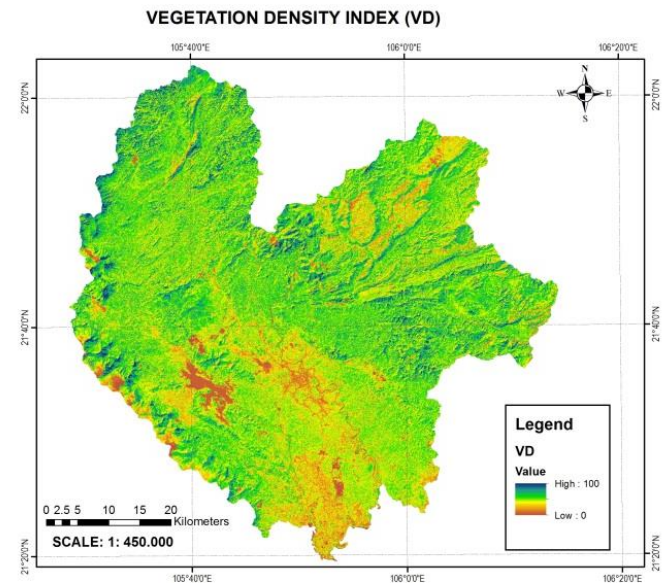

Fig. 5. Vegetation density index (VD).

$$
\mathrm{SI}=\sqrt[3]{((65536-\mathrm{B} 2) \times(65536-\mathrm{B} 3) \times(65536-\mathrm{B} 4))}
$$

where, B2 is green band, B3 is blue band and B4 is red band.

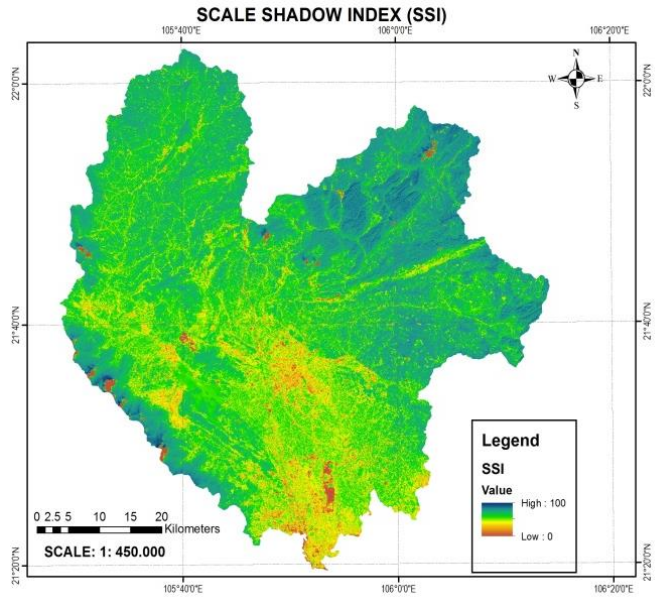

Fig. 6. Scale shadow index (SSI).

\section{5) Forest canopy density (FCD)}

FCD is one of the indices to identify the forest quality. Integration of VD and SSI means transformation for forest canopy density value [14]. VD and SSI are combined to calculate FCD and carried out as equation (5). FCD with scale from 0 to 100 percent is described in Fig. 7.

$$
\mathrm{FCD}=\sqrt{V D * S S I+1}-1
$$

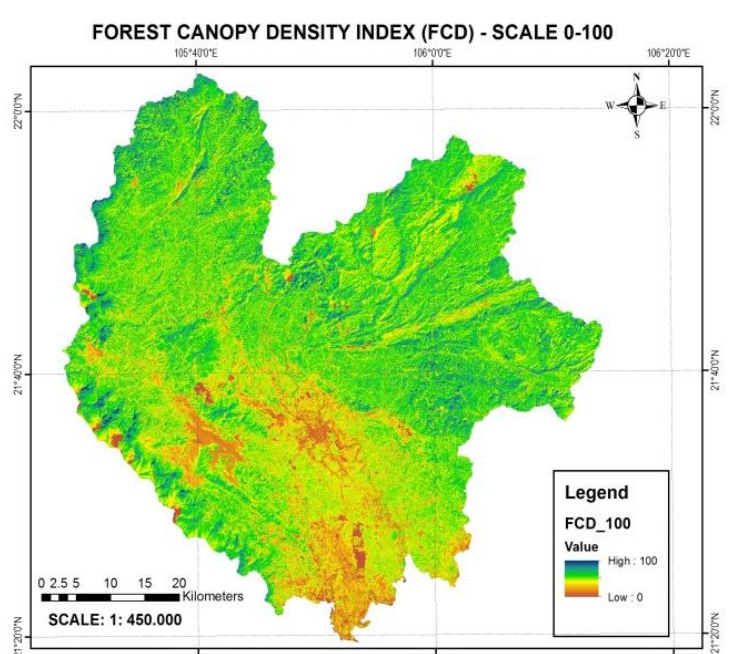

Fig. 7. Forest canopy density (FCD), scale $0-100$

\section{RESULT}

Based on the percentage, the each cell was classified into four classes of forest canopy density: dense forest density, moderate forest density, low forest density and non-forest. Dense forest density responds with the area having the value from 85 to $100 \%$. In the same manner, $50-85 \%, 15-50 \%$ and below $15 \%$ were given the moderate forest density, low forest density, and non-forest respectively (Fig. 8). The map described the distribution of forest resource in Thai Nguyen province through the FCD index. In which, the dense forest only occupied a small area along the west of study area. The majority of Thai Nguyen province is covered by moderate and low forest density. The fieldwork using land cover map was carried out to assess the accuracy of result study. The achieved result was Kappa Coefficient $=0.79$, Overall Accuracy $=85.3 \%$ (Table I).

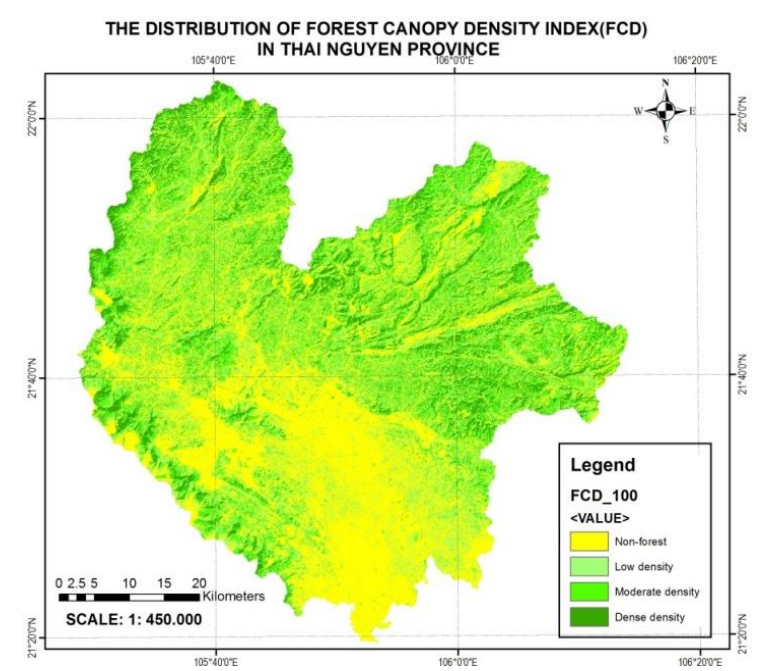

Fig. 8. Distribution of forest canopy density in Thai Nguyen province. 
TABLE I: CLASS CONFUSION MATRIX

\begin{tabular}{llllll}
\hline & Dense forest & Moderate forest & Low forest & Non-forest & Total \\
\hline Class 1 & 5251 & 302 & 15 & 33 & 5601 \\
\hline Class 2 & 250 & 3246 & 190 & 3 & 3689 \\
\hline Class 3 & 72 & 127 & 1000 & 806 & 2005 \\
\hline Class 4 & 83 & 20 & 20 & 1663 & 1786 \\
\hline Total & 5656 & 3695 & 1225 & 2505 & 13081 \\
\hline
\end{tabular}

Kappa Coefficient $=0.79$, Overall Accuracy $=85.3 \%$

\section{CONCLUSION}

The management and protection of forest resources play an extremely important role for the study area. Using GIS and remote sensing data, the achieved results have high reliability. Based on the physical properties and spectral reflection of the objects on the surface, the remote sensing images can provide much useful information in research. Landsat 8 satellite data was used to estimate the dense forest variations in a large scale in this study. The forest canopy density map expressed the forest situation of Thai Nguyen province through the level of canopy density. However, this study can develop further by using many satellite images in the different period. This helps for assessing the changes of forest canopy density over time and space. This is one of the important criteria to evaluate the forest quality and contribute the information to forest management.

\section{ACKNOWLEDGMENT}

This research was supported by GIS Research Center, Feng Chia University - Taiwan

\section{REFERENCES}

[1] S. B. Jenning, N. D. Brown, and D. Shell, "Assessing forest canopies and understory illumination: Canopy closure, canopy cover and other mearsures," Journal of Forest, vol. 1, pp. 59-73, 1999.

[2] A. Slady and S. Sailesh, "Land use/land cover and forest canopy density monitoring of wafi-golpu project area, papua new guinea," Journal of Geoscience and Environment Protection, vol. 4, pp. 1-14, 2016.

[3] J. M. Saei, "Abkar vegetation coverage canopy density monitoring using satellite images," ISPRS Comission VII, 17, Amsterdam, Holland, 2000 .

[4] H. K. Tae, K. L. Woo, A. K. Doo, P. Taejin, Y. L. Jong, Y. H. Suk, G. Cui, and R. K. So, "Forest canopy density estimation using airborne hyperspectral data," Korean Journal of Remote Sensing, pp. 297-305, 2012.

[5] Z. Azizia, A. Najafi, and H. Sohrabia, "Forest canopy density estimating using satellite images," The International Archives of the Photogrammetry, Remote Sensing and Spatial Information Sciences, Beijing, vol. 8, pp. 1127-1130, 2008.

[6] C. M. Biradar, S. Saran, P. L. N. Raju, and P. S. Royb. "Forest canopy density stratification: How relevant is biophysical spectral response modelling approach?" Geocarto International, pp. 1-7, 2005

[7] J. G. Mickelson, D. L. Civco, and J. A. Silander. "Delineating vegetation coverage canopy species in the northeastern United States using multi-temporal TM imagery," Photogrammetric Engineering \& Remote Sensing, vol. 9, pp. 891-904, 1998.

[8] J. Deka, O. P. Tripathi, and M. L. Khan, "Implementation of forest canopy density model to monitor tropical deforestation," Journal of Indian Society of Remote Sensing, vol. 41, pp. 469-475, 2012

[9] M. Pandian and R. Nandhini, "Forest canopy density and ASTER DEM based study for dense forest investigation using remote sensing and GIS techniques," International Journal of Research in Environmental Science and Technology, pp. 1- 4, 2016.

[10] W. Cuizhen and Q. Jiaguo, "Assessment of tropical forest degradation with canopy fractional cover from landsat ETM+ and IKONOS imagery," Earth Interactions, vol. 9, no. 22, pp.1-17, 2005

[11] A. Rikimaru, P. S. Roy, and S. Miyatake, "Tropical forest cover density mapping," International Society for Tropical Ecology, pp. 39-47, 2002.

[12] J. Chudamani, D. L. Jan, K. S. Andrew, C. D. Iris, and O. Henk, "Remotely sensed estimation of forest canopy density: A comparison of the performance of four methods," International Journal of Applied Earth Observation and Geoinformation, vol. 8, no. 2, pp. 84-95, 2006.

[13] K. Jai, T. Paras, and A. P. Krishna, "Forest canopy density and ASTER DEM based study for dense forest investigation using remote sensing and GIS techniques around east singhbhum in jharkhand, india," International Journal of Advanced Remote Sensing and GIS, pp. 1026-1032, 2015.

[14] S. Nandy, P. K. Joshi, and K. K. Das, "Forest canopy density stratification using biophysical modeling," Journal of the Indian Society of Remote Sensing, pp. 291-297, 2003.
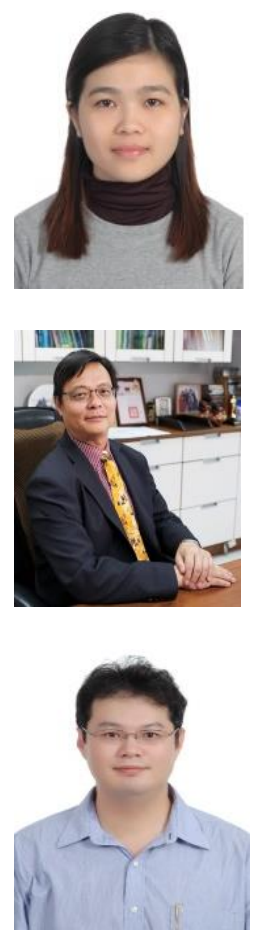

Duong Thi Loi was born in October 1988. She graduated from the Hanoi National University of Education where she obtained her master degree about geography. She is a lecturer in Hanoi National University of Education. Now she is studying for $\mathrm{PhD}$ at Feng Chia University, Taiwan. She has 7 articles published before. Her research interests are geographic information system, remote sensing, disasters prevention and urban planning.

Tien Yin Chou obtained the master degree at National Chung Hsing University in 1984 and the $\mathrm{Ph} . \mathrm{D}$ degree at Michigan State University in 1990 Currently, he is a professor in Feng Chia University and director of GIS Research Center, Taiwan. He has published many articles and book about GIS and remote sensing. His research interests are remote sensing, land management, GIS, disasters prevention and protection information.

Yao-Min Fang was born in July 1974. He received the Ph.D. degree from Feng Chia University, Taichung, Taiwan, in 2006. Before he joined the Department of Civil Engineering, Feng Chia University (FCU), in 2006, he worked as a postdoctoral researcher with the Geographic Information Systems Research Center, FCU Currently, he is a research professor with the Geographic Information Systems Research Center. His research interests include disaster monitoring and smart cities. 